\title{
RELABELLING AND MULTI-DIRECTIONALITY IN THE DEVELOPMENT OF COORDINATION
}

\author{
KUNIO NISHIYAMA \\ Ibaraki University
}

\begin{abstract}
Cross-linguistically, there is polysemy of 'with' and 'and,' which is explained as development from the comitative to the conjunction. Formally, the development is captured as change of labels from DP to \&P, which instantiates the emergence of a functional category. Coordination is decomposed into several factors, each of which changes independently. This explains several types of anomalous coordination where only some, but not all, factors have changed. Such anomalous sentences manifest the gradualness of language change, and close examination of them reveals that the change is not unidirectional but multi-directional.*
\end{abstract}

Keywords: coordination, comitative, functional categories, gradualness, directionality

\section{Introduction}

There are a number of languages where the same word is used for 'and' and 'with,' and this is by no means coincidental. Japanese to is one such example (see (4) below and section 3.3), and the Austronesian language Lamaholot also has this property: ${ }^{1}$

* Parts of this article were presented at Ibaraki University, the Lexicon Study Circle, and the 81st General Meeting of the English Literary Society of Japan (University of Tokyo at Komaba, May 2009), and I would like to thank the audiences there for comments and suggestions. I am also indebted to $E L$ reviewers and other reviewers of earlier or related versions of this article, as well as Yuji Hatakeyama, Yoshiki Ogawa, Tomoyuki Tanaka, John Whitman, and Yuko Yanagida. I also thank Herman Kelen for providing me with Lamaholot data. This study is supported by a grant from the Japan Society for the Promotion of Science (Grant \# 19520325). Errors are my own.

${ }^{1}$ Abbreviations: Defl $=$ default agreement, $\mathrm{du}=$ dual, $\mathrm{ex}=$ exclusive, $\mathrm{f}=$ feminine, Fut $=$ future, Instr $=$ instrumental, $\mathrm{m}=$ masculine, $\mathrm{Neg}=$ negation, $\mathrm{Nom}=$ nominative, $\mathrm{Obj}=$ object, $\mathrm{pl}=$ plural, $\mathrm{sg}=$ singular, Subj $=$ subject. 
(1) Lamaholot

$\begin{array}{llll}\text { a. go pana k-o'on mo } & \text { mou }\end{array}$

'I walk with you.'

b. go k-o'on mo pana

I 1sg-and you walk

'I and you walk.'

The polysemy of 'with' and 'and' has led researchers to hypothesize that there is a diachronic change from comitative marker to conjunctive marker. The purpose of this article is to investigate the structural change behind the development of coordination. It also proposes that, to capture the gradualness of the development, the notion of "coordination" should be decomposed into several independent factors.

This article is organized as follows. Section 2 motivates the change from comitative to conjunction. Section 3 presents a formal analysis of the development of coordination as emergence of a functional category that is not movement-based. Sections 4 and 5 are devoted to the discussion of gradualness in the development of coordination. In section 4, coordination is decomposed into several factors, and it is proposed that each factor can change independently, giving the impression that the change in question is gradual. But I claim that the micro-change within each factor is discrete. Section 5 presents cross-linguistic evidence where only some, but not all, factors have changed, and shows that the comitative-to-conjunctive change is multi-directional. In accord with the methodology adopted in some typological works, the discussion below is based on synchronic data ${ }^{2}$ from diverse languages (with the exception of Japanese and Chinese, where historical records are available).

The Lamaholot data in this article are based on the description of the Lewoingu dialect in Nishiyama and Kelen (2007), adapted and supplemented with the help of Herman Kelen.

Working orthography for Lamaholot (following Nishiyama and Kelen (2007)): $v=$ schwa, ' = glottal stop, word-final $n$ indicates that the preceding vowel is nasalized.

In what follows, boldfaces will be used both in examples and glosses to mark words and morphemes directly relevant for the discussion.

2 Related to this is Andersen's (2001: 228) statement that "changes are always manifested in synchronic variation." The articles in Traugott and Trousdale, eds. (2010) investigate the relationship between synchronic gradience and diachronic gradualness. 


\section{From 'with' to 'and'}

The polysemy of 'with' and 'and' is often noted in the typological literature, and because typologists are also interested in the historical development of typological diversity, they propose a hypothesis that accounts for why the same word can be used for both 'with' and 'and.' Lord (1973, 1993) provides an initial insight into this issue, proposing that in serial verb constructions, a comitative verb developed into a comitative preposition and then into a conjunction. Her insight is later elaborated by Mithun (1988) and Stassen (2000, 2001). In particular, Mithun (1988: 350) states that "[c]oordinating conjunctions can ... originate as noun phrase links from comitative constructions, then spread to predicates and clauses." See also Heine and Kuteva (2002) and Haspelmath (2004).

The direction from 'with' to 'and,' and not the other way around, is corroborated by languages where a word for a conjunction, which also has the comitative usage, can only link noun phrases. This is the case with Japanese to (Kuno (1973: 112)), Hausa da (Schachter (1985: 48)), Fijian kei (Payne (1985: 28f.)), and Twi ne (Lord (1993: 47)). In such languages, the comitative word has developed into a conjunctive word for nominals only, and has not spread to predicates and clauses.

In contrast, there are also languages where a conjunctive word, which can also be used as a comitative word, can conjoin predicates and clauses, and Lamaholot is such a language. In addition to the comitative and nominalconjoining usages as in (1), Lamaholot $-o$ 'on also conjoins predicates: ${ }^{3}$

(2) Lamaholot

mo pe'en belv n-o'on ba'a
you the big Defl-and heavy
'You are big and heavy.'

The conjunction in (2) contrasts with the equivalents in Japanese or Hausa, and suggests that the change from the comitative to the conjunction is more "advanced" in Lamaholot, indicating that -o'on has acquired a bona fide conjunctive function in (2).

Another piece of evidence comes from Chinese, where some words have established etymology. According to John Whitman (p.c.), Chinese gen

3 (2) might represent coordination of sentences with a null subject in the second sentence. But null arguments are not common in Lamaholot, so predicate coordination is more plausible. For independent reasons, pure coordination of sentences is hard to construct in Lamaholot. See Nishiyama and Kelen (2007). 
'with/and' originates as a verb, with the meaning 'accompany,' although the verbal meaning itself comes from a nominal meaning 'heel.' Moreover, gen can still be used as a verb meaning 'accompany.' Relevant examples are as follows:

(3) Chinese

a. verb:

ta gen jin lai

s/he accompany enter come

'He comes in later.'

b. comitative particle:

ni bie gen laoshi shuo nayang de hua

you not with teacher speak that kind of talk

'You should not talk to the teacher like that.'

c. conjunction:

ta gen wo yikuair qu

$\mathrm{s}$ /he and I together go

'He and I go together.'

In Japanese, to does not originate from a verb, but by the 8th century at least, the word had the polysemy of 'with' and 'and':

(4) Old Japanese

a. waga seko-to hutari mi-maseba (Man'yoosyuu 1658)

my husband-wth together see-if

'If (I) saw (this snow) together with my husband,'

b. kaguyama-to miminasiyama-to api-si

K.-and $\quad$ M.-and fight-Past

toki

(Man'yoosyuи 14)

time

'When Kaguyama and Miminasiyama had a battle,'

We return to to in Modern Japanese in section 3.3. ${ }^{4}$

${ }^{4}$ Although to can function either as a comitative preposition or as a nominal conjunction but not as a predicate conjunction (as mentioned above), it can connect a conditional clause and a result clause in Modern Japanese:

(i) tabe-sugiru-to hutoru eat-exceed-to get.fat

'When/If you overeat, you get fat.'

Although (i) does not have a coordinate meaning, this usage of to is believed to be historically derived from the comitative/conjunctive usage of to (cf. Kuno (1973: 112) and Kobayashi (1996: 210)). Thus, while Lamaholot -o'on has maintained the conjunctive meaning after becoming a predicate connective as in (2), Japanese to has lost it after the 


\section{Structural Development of Coordination: Relabelling}

In the preceding sections we have reviewed the hypothesis of the comitative-to-conjunctive change proposed in the typological literature. In contrast, to my knowledge there has been virtually no formal analysis that directly deals with the mechanisms behind the comitative-to-conjunctive change. This section tackles this issue.

\subsection{A Common Underlying Structure}

Because most typologists are also functionalists, the motivation for the comitative-to-conjunctive change proposed in the typological literature seems to be largely functional (i.e. semantic bleaching). That is, while the comitative meaning is lexical, the function of the conjunction is reduced to that of a grammatical item, hence a case of "grammaticalization." Thus, the question we should ask is, what is the formal (syntactic) relation between the two?

As far as constituency is concerned, the relevant two elements (underlined below) are discontinuous in a comitative structure (John walked with Mary), but they are continuous in a coordinate structure (John and Mary walked). Stassen (2000: 26) states that the continuous phrase in the coordinate structure is derived by "movement" of the comitative phrase to the subject. However, "movement" of a VP-adjunct into part of the subject position is unheard of, at least for the synchronic grammar of any language. Therefore, it is unlikely that movement in a theoretical sense is involved in creating a continuous coordinated noun phrase.

There is a way to relate the two structures formally: by having a common underlying structure. Ionin and Matushansky (2003) make just this kind of proposal, and the present article modifies and extends their analysis to the diachrony of coordination.

Ionin and Matushansky's analysis is primarily proposed for synchronic properties of Russian comitative and coordinate structures, but they take their analysis as universal and extend it to English with and possibly and. According to them, comitative phrases are not VP adjuncts but stranded DP adjuncts. Thus, John met with Mary has the following underlying

same process. Similar development from the nominal domain to the predicative/clausal domain is observed for Japanese $g a$, which is primarily a case marker but also functions as a sentence connective (with the meaning 'but'). 
structure:

(5) met [John with Mary]

If only John moves, we have John met with Mary. If, on the other hand, the whole DP moves, we have John with/and Mary met. ${ }^{5}$ One argument for this analysis is that it allows one to have a single argument structure for meet. If comitative and coordinate structures had different structures, there would be two entries for meet: one as a transitive requiring a comitative object (John met (with) Mary), and the other as an intransitive requiring a plural subject (John and Mary met). Such a dichotomy is unnecessary if comitative and coordinate structures have the same underlying structure.

It is not clear whether Ionin and Matushansky's proposal, according to which Russian comitative and coordinate structures have the same underlying structure of DP adjunction, can be extended to coordinate structures in other languages. In particular, as we have seen in (1b), repeated below, there is agreement between the first conjunct and the conjunction in Lamaholot:

$$
\begin{gathered}
\text { (1) b. go k-o'on mo pana } \\
\text { I 1sg-and you walk } \\
\text { 'I and you walk.' }
\end{gathered}
$$

If agreement is captured as the Spec-head relation, the coordinate structure is a projection of the conjunction and the first conjunct is in its Spec. ${ }^{6}$

I propose to modify Ionin and Matushansky's analysis as follows: comitative and coordinate structures share common underlying structures but have different labels. Using the Bare Phrase notation of Chomsky (1995), the difference is repsetented as in $(6 \mathrm{a}, \mathrm{b})$, where Co is a cover term for comitative and conjunction:

5 The alternation between with and and is a matter of morphological realization specific to English. Insights similar to that of Ionin and Matushansky have been proposed/suggested independently by researchers working on Russian. Babyonyshev (1997), cited in Progovac (2003: 247f.), is a precursor of this insight. Commenting on the example cited as (22a) in section 5.2, Vassilieva and Larson $(2005$ : 111, n. 3) suggest a similar analysis, attributing it to Anna Cardinaletti, but find it dubious. Kasai and Takahashi (2001) share the same insight in their analysis of Japanese to, to which we return in section 3.3.

${ }^{6}$ See Nishiyama (2010) for a detailed analysis of conjunctive agreement in Lamaholot. 
(6)

a. comitative

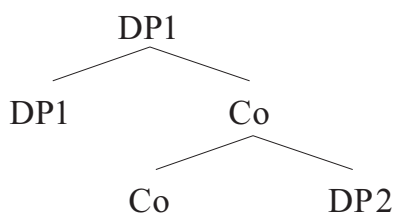

b. coordination

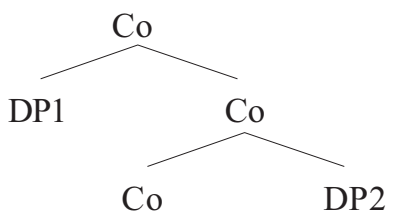

(6a) is Ionin and Matushansky's structure, where the comitative phrase is adjoined to DP1. (6b) adopts the widely accepted hypothesis (cf. Larson (1988), Kayne (1994), Johannessen (1998), and Progovac (2003), among others) that a coordinate phrase is the projection of the conjunctive word and the first conjunct is in the Spec of the projection. ${ }^{7}$

What (6) says is that comitative and coordinate constructions have a common structure until DP1 merges:

(7)

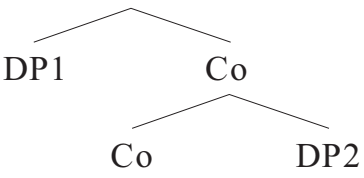

If DP1 projects, [Co DP2] would be an instance of adjunction and we have the comitative structure (6a). If, on the other hand, Co projects, we have the coordinate structure (6b). The Coordinate Structure Constraint of Ross (1967) dictates that the whole phrase, not just DP1, moves in (6b).

Now the relationship between the structures in (6) can be diachronic as well as synchronic. One important consequence in the context of the theme of this series is that the change in (6) instantiates the emergence of a functional category: while the top node in (6a) is a projection of a lexical category (DP) ${ }^{8}$ it changes to a projection of a functional category $(\mathrm{CoP})$ in (6b). However, the process involves neither of the predominating views of syntactic change: movement based or structure-expansion based (see the discussion of the movement-based theory below). To the extent that there is no structure expansion (i.e., the number of nodes remains the same between (6a) and (6b)), the change in (6) does not involve the emergence of a functional category that is simply created on top of a lexical category (cf.

${ }^{7}$ Here I assume that the constituent [Co DP2] is a projection of Co, and not a structure where DP2 is adjoined to Co. The latter structure is generally prohibited, for it contains a phrase within a head $\left(\mathrm{X}^{0}\right)$.

${ }^{8}$ Strictly speaking, DP is a functional category. But it is more "lexical" than CoP, in that the former is referential but the latter is categorially neutral. In terms of grammaticalization, CoP is more grammaticalized than DP. 
van Gelderen (1993), Tanaka's Article in this series, and the articles on the topic of functional category emergence in $E L$ 26.2; see the references in the Introduction). Rather than popping out of nowhere, the functional category in (6b) (the highest Co) has a solid basis as a lexical category in (6a) (the higher DP1).

\subsection{Theoretical Motivations}

The next question is what motivates the change in (6). Below I provide three theoretical bases for it: (i) preference for a specifier, (ii) relabelling, and (iii) economy of representation.

First, because (6) involves a change from an adjunction structure to a non-adjunction structure, it can be a direct consequence of the following principle:

(8) Be a specifier rather than an adjunct. (van Gelderen (2008: 250)) To motivate (8), van Gelderen (2008: 250) notes that:

There are also a number of changes where a new element comes from outside of the sentence, e.g., a demonstrative being incorporated into the CP to indicate subordination, and an emphatic pronoun becoming the subject (in Spec TP).

Note that DP1 in (6a) is outside the projection of Co, but DP1 in (6b) is incorporated into the projection of $\mathrm{Co}$ as the Spec, manifesting (8). ${ }^{9}$

Second, the change in (6) can also be regarded as a case of relabelling as proposed by Whitman (2000). He discusses similar V $>\mathrm{P}$ changes in serial verb constructions cited in Lord (1973), and proposes relabelling as a process distinct from movement-based diachronic change (to be discussed below). Despite the terminology (and Whitman acknowledges that it is something of a misnomer), "relabelling" in his sense changes the categorial feature of a lexical word, not the label in the bare phrase structure itself. The analysis in (6) shares the same spirit of categorial change, but

${ }^{9}$ An anonymous EL reviewer suggests that the alternation analogous to (6) and (7) is more general, citing the following Japanese example typical in a live report:

(i) Renko, basu-ni tobi-noru. Simaru doa.

R. bus-on jump-ride close door

'Renko gets on a bus. The closing door/The door closes ...'

Simaru doa looks like a DP modified by a relative clause, but the actual interpretation is more like an event. The DP structure involves adjunction of a relative clause simaru. On the other hand, with the event reading, simaru seems to be projecting up to a clause. From the perspective of the proposed analysis, we seem to have an alternation between an adjunction structure and a non-adjunction structure. 
it goes one step further and literally postulates a change in the label (i.e. relabelling) of the top node. While Whitman seeks similarities between his analysis and movement-based diachronic change in terms of change in the features of a head, I do the same thing in terms of economy of representation in the following discussion.

There is a third and more influential formal theory of syntactic change: the movement-based theory. This has been proposed independently by Roberts and Roussou (2003) and Simpson and Wu (2001) (see the Introduction to this series and below for some details). In particular, Roberts and Roussou propose that syntactic change is guided by economy of representation. Here I seek a way to incorporate Roberts and Roussou's view on syntactic change into the comitative-to-conjunctive change, and provide a third motivation for the proposed change in (6).

Roberts and Roussou do not discuss the comitative-to-conjunctive change directly, probably due to the following reasons. In their view, syntactic change is reduced to economy. Thus, the categorial change of English modals from $\mathrm{V}$ to $\mathrm{M}$ (odal) happened because it is more economical to generate modals at $\mathrm{M}$ directly than to generate them at $\mathrm{V}$ and then move them to $\mathrm{M}$ (i.e. Merge over Move). Such an account presupposes that there is a movement relation between the target (the original category) and the goal (the final category). However, such a movement relation is hard to establish between the comitative (John came with Mary) and the conjunction (John and Mary came). Thus, the comitative-to-coordination change is outside the scope of a theory of syntactic change that is based on economy and on "Merge over Move" in particular.

In fact, Roberts and Roussou (2003: 129) explicitly state that the V > P change is not a case of syntactic change as they conceive it. This is because their theory of syntactic change as economy (featuring "Merge over Move") predicts that, when there are two verbs (as in a serial verb construction), only the higher verb undergoes change, for it is closer to the upper functional head. The $\mathrm{V}>\mathrm{P}$ change typically happens to the lower verb in a serial verb construction, and, according to Lord (1973, 1993), this process is an important step toward the comitative-to-conjunctive change. Therefore, it is not surprising that the comitative-to-conjunctive change is not discussed by Roberts and Roussou (2003).

However, the comitative-to-conjunctive change can be accommodated into Roberts and Roussou's analysis. The key concept is structural simplification. One crucial point is that, Merge is more economical than (Merge plus) Move not because the former involves fewer operations (derivational 
economy), but because the former involves fewer segments (i.e. economy of representation, cf. Roberts and Roussou (2003: 16)). This concept is largely implemented as Merge-over-Move, but another instantiation is illustrated in their analysis of the development of English to from $\mathrm{P}$ to M. According to them, while the projection of preposition to is an adjunct to VP, the projection of modal to is the complement to Complementizer. They attribute this change to economy, saying "the presence of an adjunct implies the presence of an extra segment of a projection, which a complement does not" (Roberts and Roussou (2003: 106)). That is, another way to implement structural simplification is complementation over adjunction (see also Roberts and Roussou (2003: 110f.) and references therein). The same mechanism may be at work in (6). That is, DP1 changes from an adjoined target in (6a) to a specifier in $(6 \mathrm{~b})$, and $(6 \mathrm{~b})$ no longer contains an adjunction.

\subsection{Extensions}

Section 3.1 has presented the development of coordination from a comitative preposition. However, according to Lord (1973, 1993), before the preposition stage, there is a stage of a comitative verb as the origin of the conjunction. This section discusses such a case. It also considers coordination in head-final languages.

The essence of Ionin and Matushansky's analysis endorsed in section 3.1 is that in the comitative construction, only the first DP raises to the subject position, stranding the comitative phrase. This yields a discontinuous string, as in John walked $t$ with Mary. In contrast, with the comitative verb, there would be no movement that would disrupt the linear order of [DP1 Co DP2], for Co is identified with the matrix verb. The same situation holds in the final stage of coordinate structure, where the whole conjoined phrase moves to the subject position. These three situations are schematized as follows:

(9) a. comitative verb

[DP1 V DP2] (John accompanied Mary.)

b. comitative preposition

$$
\mathrm{V}[\underline{\mathrm{DP} 1}[\mathbf{P} \text { DP2 }]] \quad\left(\mathrm{John}_{\mathrm{i}} \text { walked } t_{\mathrm{i}} \text { with Mary. }\right)
$$

c. conjunction

$$
\text { V } \underset{[\& \mathrm{P}}{\rfloor} \mathrm{DP} 1[\boldsymbol{\&} \mathrm{DP} 2]] \text { ([John and Mary }]_{\mathrm{i}} \text { walked } t_{\mathrm{i}} \text { ) }
$$

Only in (9b) is the constituent [DP1 Co DP2] disrupted, where Co is a cover term for the comitative verb $(\mathrm{V})$, the comitative preposition $(\mathrm{P})$ and 
the conjunction (\&). That is, as far as constituency is concerned, there is a cycle as in (10):

(10) comitative verb $>$ comitative preposition $>$ conjunction (continuous) (discontinuous) (continuous)

Discontinuous strings are derived in $(9 \mathrm{~b})$ because it describes a situation of verb-medial languages. In verb-final languages, in contrast, there would be no situation where the matrix verb comes between DP1 and DP2. Still, comitative and coordinate constructions are distinguished, as in the following Japanese examples:

(11) Japanese

a. Mary-ga John-to aruita

Mary-Nom John-with walked

'Mary walked with John.'

b. John-to Mary-ga aruita

John-and Mary-Nom walked

'John and Mary walked.'

(cf. Kuno (1973))

$(11 \mathrm{a}, \mathrm{b})$ are derived as in $(12 \mathrm{a}, \mathrm{b})$, respectively:

(12) a. comitative

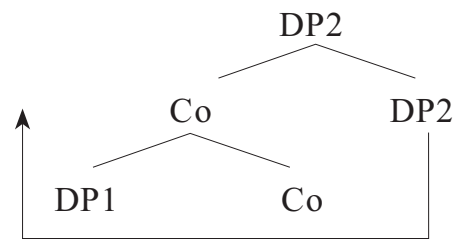

b. coordination

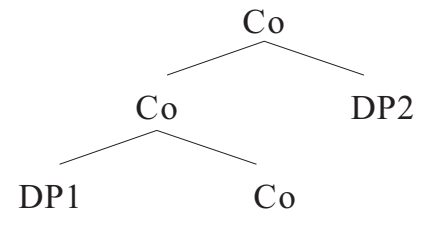

Here, DP1 is John and DP2 Mary. (12a, b) are mirror images of (6a, b), which represent the comitative/coordinate structures proposed for headinitial languages. (12a) is independently proposed for Japanese by Kasai and Takahashi (2001: 24), although they do not assume movement of DP2. (12b) is the structure of coordination in head-final languages proposed by Johannessen (1998: 109). Note that there is reordering of DP1 and DP2 in (12a); DP2 precedes DP1 after movement. ${ }^{10}$

${ }^{10}$ As noted by Kuno (1973: 117), there is further reordering when a comitative phrase scrambles:

(i) $[\text { John-to }]_{\mathrm{i}}$ Mary-ga $t_{\mathrm{i}}$ aruita John-with Mary-Nom walked

'With John, Mary walked.'

Thus, the string $D P$-to $D P$ is actually ambiguous between a coordinate structure and a scrambled comitative structure. 


\section{Decomposing Coordination}

In this and the following sections I discuss the issue of gradualness in the development of coordination. I propose that the notion of "coordination," especially that of nominals, is an epiphenomenon; it is to be decomposed into independent factors, and each factor can change independently. ${ }^{11}$

4.1. Independence of Syntax, Morphology, and Semantics

As typical cases of comitative/coordinate constructions, consider the following Lamaholot examples:

(13) Lamaholot

$$
\begin{aligned}
& \text { a. go k-enun k-o'on Bala } \\
& \text { I 1sg-drink 1sg-with B. } \\
& \text { 'I drink with Bala.' }
\end{aligned}
$$
b. go k-o'on Bala m-enun
I 1sg-o'on B. 1pl.ex-drink
'I and Bala drink.'

I propose that the change from (a) comitative to (b) coordination involves several independent changes as follows:

(14) The Development of Coordination Decomposed

$$
\text { (a) comitative }>\text { (b) coordination }
$$

\begin{tabular}{|l|l|ll|}
\hline \multirow{2}{*}{ syntax } & category & V/P & $>\&$ \\
\cline { 2 - 4 } & constituency & $($ dis $)$ continuous & $>$ continuous \\
\hline morphology & agreement & singular & $>$ plural \\
\hline semantics & controllability & asymmetric & $>$ symmetric \\
\hline
\end{tabular}

As we have seen in the previous section on the syntactic development of coordination, there is a correlation between categorial change and constituency change. This is observed in (13): DP1 and DP2 are discontinuous in the comitative construction (a) but continuous in the coordinate construction (b). But constituency is not helpful when a comitative verb is involved, for DP1 and DP2 are continuous in such a case (cf. (9a)). When a comitative verb is involved, then, different criteria must be used for the identification of verbs. In section 5.1, I utilize selection by $\mathrm{T}$ and case-licensing ability

11 In a similar vein, Warner (1997) proposes that the loss of verb movement in English involves several parametric changes. 
as hallmarks of the verbal nature of a conjunctive marker.

Let us next discuss morphology. Since coordination consists of at least two entities, when a coordinated phrase becomes the subject, the verbal agreement, if any, must be plural (or dual), as in (13b). ${ }^{12}$ In contrast, the subject in a comitative construction can be singular, as in (13a).

One might claim that the Lamaholot conjunctive marker -o'on in (13) is a verb, for it shows agreement. It is likely that agreement reflects the verbal source of the word, but the point of this article is that syntax and morphology can change independently. Thus, even if a word shows agreement, it is possible that it is no longer a verb. The independence of agreement and verbal property is also observed in complementizer agreement in Dutch (cf. Ackema and Neeleman (2004: 249) and references therein).

As for the semantic criteria of controllability, a comitative construction describes a situation where one of the two participants has control over the event. In a coordinate structure, in contrast, the two participants have the same degree of control over the event, or the two participants do not perform the events simultaneously. To use English examples, in John and Mary came, John and Mary have the same control over the event of coming and the two events of John's coming and Mary's coming do not have to be simultaneous. On the other hand in John came with Mary, John has control over the event, and John's coming and Mary's coming must be simultaneous. In formal terms, the presence of a conjunctive marker reflects an increase in the complexity of the event structure, as proposed by Progovac (1999, 2003).

Given the autonomy of components of grammar, I propose that the changes in (14) can happen independently. ${ }^{13}$ One consequence of this hypothesis is that there are several types of intermediate stages where only some, but crucially not all, factors have changed, and section 5 is devoted to showing that this prediction is correct. But before that, I discuss in the following subsection how this view of language change contributes to our understanding of directionality and gradualness of syntactic change, and how it can be accommodated into the generative model that features discreteness (see the Introduction to this series).

12 Only a subset of verbs show agreement in Lamaholot; -enun 'drink' is such an agreeing verb, while pana 'walk' as in (1) is not. See Nishiyama and Kelen (2007) for details.

13 McMahon (1994: 161) refers to this situation as "cross-componental change." 
4.2. Directionality, Gradualness and Discreteness

One important question is whether the change from the comitative to the conjunction is unidirectional. Assuming the unidirectionality hypothesis for grammaticalization, Stassen (2000: 27) claims that verbal morphology taking dual or plural agreement is a sign that the comitative-to-conjunctive change is complete. Although not as articulated as (14), Stassen also seems to assume that coordination has several factors, and his analysis implies that the morphological change comes last in the comitative-to-conjunctive change.

I will show in the next section that Stassen's hypothesis cannot be correct, based on cross-linguistic evidence where the morphological change has occurred while some other type of change (syntactic and/or semantic) has not. That is, there is no fixed ordering such as semantic change $\rightarrow$ syntactic change $\rightarrow$ morphological change (there is no intrinsic order between each of them). In other words, the comitative-to-conjunctive change is multi-directional.

As a reviewer points out, however, there is unidirectionality hidden in (14), and that is within each factor, i.e. between properties which constitute a factor specific to each type of change. For example, the categorial change goes from $\mathrm{V} / \mathrm{P}$ to $\&$, and not the other way around. As schematized below, I assume that the changes $\mathrm{A} \rightarrow \mathrm{B}$ and $\mathrm{C} \rightarrow \mathrm{D}$ may be unidirectional, while $\alpha$ and $\beta$ are not ordered:

(15) change $\alpha: \quad A \rightarrow B$ change $\beta: \quad C \rightarrow D$

In other words, in the decomposed view of constructions, historical changes are two-dimensional. Utilizing (15), it is my conception that, while the change in the horizontal dimension may be unidirectional, there is no directionality in the vertical dimension, yielding multi-directional change.

It is often claimed that language change is cyclic, as attested in the change in constituency in (10). If this is correct, the change $\mathrm{A} \rightarrow \mathrm{B}$ may not be unidirectional and there could be a case of $\mathrm{B} \rightarrow \mathrm{A} \cdot{ }^{14}$ Although I do not take a definitive stance as to the direction of change within each factor, the major claim of this article is that there is no order across the various factors, as between $\alpha$ and $\beta$ above.

Whether unidirectional or not, the change within a factor provides a key

14 Yuji Hatakeyama (p.c.) points out that bread and butter may be a case of \& > P, contrary to (14). Thus, while and starts out as the conjunctive marker here, it has the meaning close to with, a preposition. In addition, and has undergone phonological reduction (as bread 'n' butter), typical of grammaticalization. 
for accommodating discreteness into gradual change. As mentioned in the Introduction to this series, with discreteness as its core feature, a generative approach to syntactic change must formulate a model where there is no intermediate status of an item. This character is observed within each factor in (14). For example, verbal agreement is either singular or plural, and cannot be both singular and plural simultaneously. In the next section we will see many cases of "intermediate" stages, but I will characterize them as cases where only some, but not all, of the factors in (14) have changed. Crucially, despite the impression of gradualness, if we focus on a single factor, the relevant changes have either happened or not, and there is no intermediate or ambivalent stage. ${ }^{15}$

\section{Anomalous Coordination and Multi-directionality}

With the hypothesis that (each type of) the changes in (14) can happen independently, we predict that there are sentences where only one or two of those change(s) can be observed. This section presents some concrete examples. Such sentences are usually considered anomalous, in the sense that they show mixed properties of comitative and coordinate structures. In my view, such anomalies manifest situations where only some, but not all, of the factors in (14) have changed.

\subsection{Agreement Mismatch and Verb-like Conjunctions}

We have seen that Lamaholot $-o$ 'on can be used as a comitative marker (13a), as a nominal conjunctive marker (13b), and as a predicate conjunctive marker (2) (repeated):

(13) Lamaholot
a. go k-enun k-o'on Bala
I 1sg-drink 1sg-with B.
'I drink with Bala.'
b. go k-o'on Bala m-enun
I 1sg-o'on B. 1pl.ex-drink
'I and Bala drink.'

\footnotetext{
15 Traugott and Trousdale (2010) and Roberts (2010) share the same view, stating that "most instances of change involve small micro-steps that are in fact discrete and therefore abrupt (in a tiny way)" (Traugott and Trousdale (2010: 20)), and "a seemingly analogue cline or curve can in fact be broken down into many small, but discrete, individual steps" (Roberts (2010: 65)).
} 
(2) mo pe'en belv n-o'on ba'a
you the big Defl-and heavy

'You are big and heavy.'

In Acehnese, an Austronesian language closely related to Lamaholot, a comitative/coordinate sentence is as follows:

(16) Acehnese

lôn ngön-adek lôn-jak bak-sikula

I and/with-younger.brother 1sg-go to-school

'I and my younger brother go to school/I go to school with my brother.'

(Durie (1985: 124)/Stassen (2000: 30))

Although a noun phrase containing ngön (possibly cognate with Lamaholot (n)o'on) can trigger alternative plural agreement on the verb, agreement can also be singular as in (16). This contrasts with the above Lamaholot counterpart in (13b), where plural agreement is required. (16) is a case where neither the change in verbal morphology nor (in the case of the comitative interpretation) the semantic change has occurred.

As shown in (13), Lamaholot is a language where the conjunctive marker shows agreement. Walman, a Torricelli language of Papua New Guinea, is another language with conjunctive agreement. Although the language is genetically unrelated to Lamaholot, it may well be related areally, and its descriptions by Brown and Dryer (2008) show peculiar contrasts with Lamaholot. ${ }^{16}$ As shown in (2), the Lamaholot conjunctive marker can conjoin predicates. In contrast, the Walman conjunctive words do not seem to have the function of conjoining predicates. In fact, the major claim of Brown and Dryer is that the conjunctive word in Walman is also a verb. Thus, the first conjunct is the subject of the verb 'and,' and the second conjunct the object thereof.

Consider the following examples:

(17) Walman
a. $\mathrm{ru}$
ruon
w-klwaro-n
3sg.f 3sg.f-deceive-3sg.m 3sg.m
'She deceived him.'
b. Vanessa mon w-a-n Amos y-o ro $<y>$ rani Vanessa Neg 3sg.f-and-3sg.m Amos 3pl-be tall $<$ pl $>$ 'Vanessa and Amos are not tall.'

16 See Nishiyama (2010) for detailed comparisons between Lamaholot and Walman. 


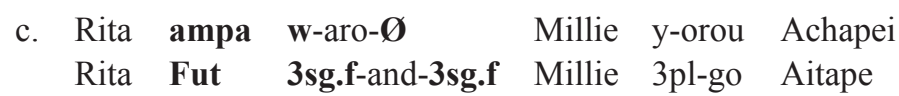
Rita ampa w-orou eni, Millie ampa w-orou pichi Rita fut 3sg.f-go now Millie fut 3sg.f-go tomorrow 'Rita and Millie are going to go to Aitape. Rita will go today and Millie will go tomorrow.'

(Brown and Dryer (2008: 532, 547, 556))

In Walman, verbs agree with the subject by a prefix and with the object by a suffix, as shown by the verb $\boldsymbol{w}$-klwaro-n '3sg.f-deceive-3sg.m' in (17a). In (17b), the conjunctive marker $\boldsymbol{w}$-a-n '3sg.f-and-3sg.m' shows similar agreement, agreeing with the first conjunct by a prefix and with the second conjunct by a suffix. What is peculiar here is that the translation and the plural agreement on the matrix predicate 'be tall' (as well as its stative meaning) indicate that the subject of the sentence is a coordinated noun phrase. However, the negative morpheme mon (glossed as Neg), which semantically negates the whole sentence, precedes the conjunctive marker. Therefore, the conjunction in (17b) has the verbal property of being selected by the negation. (17c) shows the same point: the conjunctive word is preceded by a tense marker ampa (glossed as Fut). The second sentence in $(17 \mathrm{c})$ is provided to exclude the comitative interpretation.

On the assumption that the negation and the tense markers are clausal particles, Brown and Dryer argue that Vanessa mon w-a-n Amos and Rita ampa w-aro- $\varnothing$ Millie above are clauses, and that the conjunctive word in Walman is a verb. Brown and Dryer (2008: 541, n. 19) state that "if this construction is currently undergoing the process by which it is acquiring nominal features, then that process is not still completed." In the terms of the present article, Walman conjunctive constructions are at the stage where the semantic and agreement changes have occurred, but crucially the categorial change has not.

Engenni, a Kwa language of West Africa, is another language where the conjunctive marker retains its verbal properties. Consider:

(18) Engenni

a. mì nàà ìwó si ta nì

I.Subj and you.Obj will go def

'You and I will be the ones to go.'

b. o mòni enì nàà asunu enì

he saw we.Subj and father our

'He saw our father and us.'

(Lord (1993: 49))

Engenni has distinct forms for subject pronouns and object pronouns. The 
above sentences show that when a pronoun precedes the conjunction, the subject form is used, and when a pronoun follows the conjunction, the object form is used. This is true regardless of whether the coordinated phrase is the subject or the object of the sentence. Thus, the conjunctive marker nàa in (18) still retains its verbal property of case-licensing. In our terms, the conjunction shows a stage in which the categorial change has not yet occurred.

\subsection{Inclusory Pronouns}

Another case of an intermediate stage is shown by inclusory pronouns. ${ }^{17}$ The following Russian examples illustrate this construction:

(19) Russian

a. Anna pridët $\mathbf{s}$ Petej

A.Nom come.3sg with P.Instr

'Anna is coming with Peter.'

b. Anna s Petej napisali pis'mo

A.Nom and P.Instr wrote.pl letter

'Anna and Peter wrote a letter.'

c. my s Petej pojdëm domoj

we with/and P.Instr go-Fut home

'We will go home with Peter.'

'I and Peter will go home.'

(cf. McNally (1993), Vassilieva and Larson (2005))

(19a) illustrates a canonical comitative construction. (19b) shows that, in addition to the comitative usage as in (19a), $s$ can be used as a conjunction. That Anna s Petej is a coordination, not an adjunction structure, is suggested by the plural agreement on the verb, on the assumption that the sentence involves canonical agreement. (19c) is ambiguous, and its second meaning in the translation is the case of the inclusory pronoun. Note that, unlike the first interpretation of an ordinary pronoun, there are only two participants in the second interpretation. Thus, a better translation might be 'We, one of us being Peter, will go home' (cf. Lichtenberk (2000)). This construction is observed in many languages of various families (see Dyla (1988), Schwartz (1988), Aissen (1989), McNally (1993), Camacho (2000), Lichtenberk (2000), Abdoulaye (2004), Vassilieva and Larson (2005) and

17 They are alternatively called plural pronouns. The term "inclusory" is due to Lichtenberk (2000). 
references therein).

I propose that inclusory pronouns emerge when each type of changes in (14) happens in a particular order as specified in (20):

$\begin{array}{lllllll}\text { (20) } & \text { Stage 1 } & \text { I } & \text { V-sg } & \text { Co } & \text { NP } & \text { 'I do something with NP.' } \\ \text { Stage 2 } & \text { I } & \text { V-pl } & \text { Co } & \text { NP } & \text { 'I and NP do something.' } \\ \text { Stage 3 } & \underline{\text { We }} & \text { V-pl } & \text { Co } & \text { NP } & \text { 'I and NP do something.' } \\ \text { Stage 4 } & \underline{\mathrm{We}} & \text { Co NP } & \text { V-pl } & \text { 'I and NP do something.' }\end{array}$

This is a consequence of the proposed view of diachronic change in a construction where several factors change independently. Stage 1 is the initial state with a comitative construction. At Stage 2, the semantic and morphological changes have occurred, yielding the conjunctive interpretation and plural agreement on the main verb. This creates a situation of agreement mismatch between the subject and the verb. Such a situation leads to the next stage, an important step toward the emergence of inclusory pronouns. In Stage 3, the singular pronoun changes to the plural counterpart, but this is purely morphological, in accordance with the plural agreement on the verb. Crucially, the meaning remains the same, 'I and NP do something.' In the final step of Stage 4, the constituency change has taken place, resulting in a continuous coordinate noun phrase.

The trigger of the change in Stage 2 might be the increased complexity of the event structure (see section 4.1). The situation in Stage 2 is attested in the following examples:

a. Acholi (Nilo-Saharan, Nilotic)

òkeelò gï-ciïtò paàco gïïn ki làmïnne

O. 3pl-go home $3 \mathrm{pl}$ and/with sister.his

'Okeelo and his sister went home.'

(Crazzolara (1955: 66)/Stassen (2000: 30))

b. Tolai (Austronesian, Melanesian)

telengai dir rovoi ma ra pap

T. 3du hunt and/with article dog

'Telengai and the dog hunted.'

(Mosel (1984: 176)/Stassen (2000: 30))

In (21a), the singular subject triggers plural agreement on the verb gï-ciïtò '3pl-go,' as in Stage 2 in (20). In (21b), the singular subject is doubled with the third dual pronoun. This doubled pronoun, also observed in (21a) (giïn), can be the origin of inclusory pronouns.

The analysis in (20) also predicts that inclusory pronouns can be observed with discontinuous phrases, as in Stage 3. This is partially confirmed by the above sentences in (21). More concrete evidence is provided for Russian 
in (22a) and Yapese (Micronesian) in (22b):

(22)

a. Russian

$\underline{\text { my }}$ pojdëm zavtra $\underline{\mathrm{s} \quad \text { Ivanom }} \mathrm{v}$ magazi $\mathrm{i}$ vsë

we go-Fut tomorrow with Ivan to store and all

kupim

buy-fut

'Ivan and I will go to the store and get all (we need).'

(Vassilieva and Larson (2005: 111f.))

b. Yapese

yow bea marweel Tamag

$3 \mathrm{du}$ present.progress work $\mathrm{T}$.

'He and Tamag are working.' (Lichtenberk (2000: 4))

In (22a), in addition to the ordinary pronoun meaning 'We'll go with Ivan,' the sentence has the inclusory pronoun interpretation, as in the translation. Note that, although the meaning is conjunctive, the first and the second conjuncts are separated. The same situation holds in Hausa (Abdoulaye (2004: 166, 185)). In (22b) as well, although the comitative/ conjunctive marker is not overt, the second conjunct is separated. Aissen (1989: 522) provides a similar example from Tzotzil. Those are instantiations of Stage 3 in (20).

The importance of inclusory pronouns is that, while one may dismiss previous examples in section 5.1 as minor anomalous cases, inclusory pronouns are quite widespread cross-linguistically, ranging over a wide variety of language families (see the above references and Vassilieva and Larson (2005: 102)). Thus, grammar must accommodate a mechanism to generate such a construction. Another important aspect of inclusory pronouns is that there is a strong correlation between inclusory pronouns and the isomorphism of the comitative and the conjunction (as in Russian). That is, in many of the languages that have inclusory pronouns, the same word is used for 'with' and 'and.' The scenario in (20) directly explains this correlation. ${ }^{18}$

18 The correlation might be obscured when a language creates a word that is exclusively used as the conjunction (cf. Mithun (1988)). Just as there are several sources for coordination (ibid.), comitative constructions are not the only source for inclusory pronouns. This is why some languages (e.g. Romance) with distinct entries for the comitative and the conjunction can have inclusory pronouns. Additionally, subsequent loss of agreement might obscure the scenario in (20). 
5.3. Summary and Consequences

The anomalous sentences discussed in this section are summarized as follows:

(23) Multi-directionality of the Comitative-to-Conjunctive Change

\begin{tabular}{|l|l|l|l|l|}
\hline & agreement & category & constituency & controllability \\
\hline Acehnese (16) & No & & Yes & Yes/No \\
\hline Walman (17b, c) & Yes & No & Yes & Yes \\
\hline Engenni (18) & & No & Yes & Yes \\
\hline Acholi (21a) & Yes & & No & Yes \\
\hline Russian (22a) & Yes & & No & Yes \\
\hline
\end{tabular}

The Yes cell indicates that the relevant change has happened, and the No cell indicates that it has not. Blank cells indicate that there is no direct evidence. As the table shows, every example has at least one No cell. This suggests that there is no uniform path for the four changes, and that each change can happen independently. This is the essence of the decompositional view of diachronic change.

For the rest of this section I discuss consequences of the proposed view of historical change. Anomalous sentences of the sorts featured in this section are usually not discussed in the generative literature. This is probably because such sentences are simply untreatable in theoretical terms. Consider again the Walman example (repeated):

$$
\begin{array}{llllll}
\text { c. Rita } & \text { ampa } & \text { w-aro-Ø } & \text { Millie } & \text { y-orou } & \text { Achapei } \\
\text { Rita } & \text { Fut } & \text { 3sg.f-and-3sg.f } & \text { Millie } & \text { 3pl-go } & \text { Aitape }
\end{array}
$$

'Rita and Millie are going to go to Aitape. (Rita will go today and Millie will go tomorrow.)'

As we saw in section 5.1, Brown and Dryer (2008) argue that -aro- is a verb and Rita ampa w-aro-Ø Millie is a clause. However, the constituent is more like a nominal semantically, for it denotes a set of entities. ${ }^{19}$ This is a puzzle, for clausal arguments usually denote a proposition (as in [That John hit Bill] surprised Mary), not a set of entities as in (17c). In other words, Rita ampa w-aro- $\varnothing$ Millie is TP syntactically but \&P (or DP) semantically.

19 In the \&P hypothesis, the categorial feature of the whole \&P is determined by the first conjunct (cf. Johannessen (1998: 111)). This guarantees that John and Mary is a nominal, even though it is of category \&P. 
One typical way out of this problem is to seek a (somewhat abstract) analysis that is compatible with conventional views of clause structure. Thus, a headless relative clause analysis of the subject in $(17 \mathrm{c})$ changes the apparent clause into a nominal. Alternatively, a second position clitic analysis of ampa enables it to modify the matrix clause and no longer allows the clause analysis of Rita ampa w-aro- $\varnothing$ Millie. However, neither of the analyses is supported by Brown and Dryer (2008). Brown and Dryer (2008: 547, n. 27) explicitly say that mon and ampa in (17) cannot be second position clitics. They also note (n. 28) that the sentences in (17) are not plausibly analyzed as involving headless relative clauses. ${ }^{20}$

It seems to be a common assumption that grammatical principles in general are intended to account for canonical sentences and that anomalous sentences are outside of their scope. But that position begs the question of what canonical sentences are. The fact that there is no language at the "final" stage and that every language is in the process of changing seems to raise the possibility that every sentence is in an intermediate stage and is thus anomalous. At the same time, however, we also have the intuition that certain stages are stable. In the case at hand, coordination is stable when all four of the changes in (14) are completed. Thus, John and Mary come is stable because (i) John and Mary have equal controllability over the event, (ii) and is neither a verb nor a preposition, (iii) John and Mary form a continuous constituent, and (iv) that constituent induces plural agreement. Although "stable" does not mean that the situation will never change, the state will presumably last for a substantial period of time, and this is where ordinary grammatical principles apply. In short, although I propose that anomalous sentences can be handled in theoretical terms (featuring discreteness) if we decompose a language change into several factors, this position does not necessarily imply that anomalous sentences should and can be given straightforward analyses as canonical sentences.

Let us finally consider the proposed multi-directional view of language change in connection with Roberts' (2001) and Roberts and Roussou's (2003: 7) claim that "certain parameter values tend to covary." If, as proposed in the present article, the comitative-to-conjunctive change is

20 John Whitman (p.c.) suggests a variant of a headless relative clause analysis, according to which a null pronoun refers to the two conjuncts, as Rita is like Millie: pro go to Aitape. In this analysis, the comitative verb does not denote physical accompanying but sharing of a common property; recall that (17c) describes a situation where Rita and Millie go on different days. 
multi-directional, this indicates that covariations in Roberts and Roussou's sense are not absolute, and they in fact acknowledge that covariations are tendencies. But to the extent that there is a strong basis for the covariations, language change is more or less deterministic (i.e. unidirectional). In other words, an apparent violation of principles in a transitional period can be a cause of a further chain reaction, leading to completion of the language change and yielding "canonical" sentences where no principle of grammar is violated.

\section{Conclusion}

This article has made two major claims. Syntactically, the development from the comitative structure to the coordinate structure is analyzed as change of the label from DP to CoP, and this instantiates the emergence of a functional category that is based on neither movement nor structure expansion. I also claimed that coordination should be decomposed into several factors, which can change independently. This decomposition allows us to analyze several types of anomalous coordination. In such anomalous sentences, some, but not all, factors of coordination have changed. The analysis implies that the comitative-to-conjunctive change is not unidirectional but multi-directional. Anomalous sentences are usually not treated in the generative literature, but I have shown that, by decomposing coordination, they can be treated in formal terms. Despite the apparent gradualness of the macro-change, if we focus on the micro-change in each factor, it has or has not changed, ${ }^{21}$ and there is no intermediate stage within the factor. This confirms one of the central theses of generative grammar, namely that human language is discrete in nature, and that shows this property also plays a role in language change.

\section{REFERENCES}

Abdoulaye, Mahamene L. (2004) "Comitative, Coordinating, and Inclusory Constructions in Hausa," Coordinating Constructions, ed. by Martin Haspelmath, 165-193, John Benjamins, Philadelphia.

21 The distinction between macro-change and micro-change is also termed diachronic correspondence and (real) change, respectively. See Andersen (2001: 228, 2008: 12), Norde (2009: 35) and references therein. 
Ackema, Peter and Ad Neeleman (2004) Beyond Morphology, Oxford University Press, New York.

Aissen, Judith L. (1989) "Agreement Controllers and Tzotzil Comitatives," Language $65,518-536$.

Andersen, Henning (2001) "Actualization and (Uni)directionality of Change," Actualization: Linguistic Change in Progress, ed. by Henning Andersen, 225-248, John Benjamins, Philadelphia.

Andersen, Henning (2008) "Grammaticalization in a Speaker-oriented Theory of Change," Grammatical Change and Linguistic Theory, ed. by Thórhallur Eythórsson, 11-44, John Benjamins, Philadelphia.

Babyonyshev, Maria (1997) "Covert Feature Checking and Conjunction Agreement in Russian," paper presented at Formal Approaches to Slavic Linguistics, University of Connecticut, Storrs.

Brown, Lea and Matthew S. Dryer (2008) "The Verb for 'and' in Walman, a Torricelli Language of Papua New Guinea," Language 84, 528-565.

Camacho, José (2000) "Structural Restrictions on Comitative Coordination," Linguistic Inquiry 31, 366-375.

Chomsky, Noam (1995) The Minimalist Program, MIT Press, Cambridge, MA.

Crazzolara, Joseph P. (1955) A Study of the Acooli Language, Oxford University Press, London.

Durie, Mark (1985) A Grammar of Acehnese, Foris, Dordrecht.

Dyla, Stefan (1988) "Quasi-Comitative Coordination in Polish," Linguistics 26, 383-414.

Gelderen, Elly van (1993) The Rise of Functional Categories, John Benjamins, Philadelphia.

Gelderen, Elly van (2008) "Linguistic Cycles and Economy Principles," Grammatical Change and Linguistic Theory, ed. by Thórhallur Eythórsson, 245-264, John Benjamins, Philadelphia.

Haspelmath, Martin, ed. (2004) Coordinating Constructions, John Benjamins, Philadelphia.

Heine, Bernd and Tania Kuteva (2002) World Lexicon of Grammaticalization, Cambridge University Press, Cambridge.

Ionin, Tania and Ora Matushansky (2003) "DPs with a Twist: A Unified Analysis of Russian Comitatives," Annual Workshop on Formal Approaches to Slavic Linguistics: The Amherst Meeting, ed. by Wayles Browne, Ji-yung Kim, Barbara Partee and Robert Rothstein, 255-274, Michigan Slavic Publications, Ann Arbor. Johannessen, Janne Bondi (1998) Coordination, Oxford University Press, New York.

Kasai, Hironobu and Shoichi Takahashi (2001) "Coordination in Japanese," MIT Working Papers in Linguistics 41, 19-32.

Kayne, Richard (1994) The Antisymmetry of Syntax, MIT Press, Cambridge, MA.

Kobayashi, Kenji (1996) Nihongo Zyookenhyoogensi no Kenkyuu (A Study on the History of Conditional Expressions in Japanese), Hituzi Syobo, Tokyo.

Kuno, Susumu (1973) The Structure of the Japanese Language, MIT Press, Cambridge, MA. 
Larson, Richard S. (1988) "On the Double Object Construction," Linguistic Inquiry 19, 335-391.

Lichtenberk, Franstek (2000) "Inclusory Pronominals," Oceanic Linguistics 39, 1-32.

Lord, Carol (1973) "Serial Verbs in Transition," Studies in African Linguistics 4, 269-296.

Lord, Carol (1993) Historical Change in Serial Verb Constructions, John Benjamins, Philadelphia.

McMahon, April M. S. (1994) Understanding Language Change, Cambridge University Press, Cambridge.

McNally, Louise (1993) "Comitative Coordination: A Case Study in Group Formation," Natural Language and Linguistic Theory 11, 347-379.

Mithun, Marianne (1988) "The Grammaticalization of Coordination," Clause Combination in Grammar and Discourse, ed. by John Haiman and Sandra A. Thompson, 331-359, John Benjamins, Philadelphia.

Mosel, Ulrike (1984) Tolai Syntax and Its Historical Development, Pacific Linguistics, Series B, no. 92, Dept. of Linguistics, Research School of Pacific Studies, Australian National University.

Nishiyama, Kunio (2010) "Conjunctive Agreement in Lamaholot," Journal of Linguistics, doi:10.1017/S0022226710000356, published online by Cambridge University Press [http://journals.cambridge.org/action/displayJournal?jid=LIN]. To appear in Journal of Linguistics 47 (2011).

Nishiyama, Kunio and Herman Kelen (2007) A Grammar of Lamaholot, Eastern Indonesia: The Morphology and Syntax of the Lewoingu Dialect, Lincom, Munich.

Norde, Muriel (2009) Degrammaticalization, Oxford University Press, New York.

Payne, John R (1985) "Complex Phrases and Complex Sentences," Language Typology and Syntactic Description: Complex Constructions, ed. by Timothy Shopen, 3-41, Cambridge University Press, Cambridge.

Progovac, Ljiljiana (1999) "Events and Economy of Coordination," Syntax 2, 141159.

Progovac, Ljiljiana (2003) "Structures for Coordination," The Second GLOT International State-of-the-Aritcle Book, ed. by Lisa Cheng and Rint Sybesma, 241-287, Walter de Gruyter, Berlin.

Roberts, Ian (2001) "Language Change and Learnability," Language Acquisition and Learnability, ed. by Stefano Bertolo, 81-125, Cambridge University Press, Cambridge.

Roberts, Ian (2010) "Grammaticalization, the Clausal Hierarchy and Semantic Bleaching," Gradience, Gradualness and Grammaticalization, ed. by Elizabeth Closs Traugott and Graeme Trousdale, 45-73, John Benjamins, Philadelphia.

Roberts, Ian and Anna Roussou (2003) Syntactic Change: A Minimalist Approach to Grammaticalization, Cambridge University Press, Cambridge.

Ross, John R. (1967) Constraints on Variables in Syntax, Doctoral dissertation, MIT. [Published as Infinite Syntax! by Ablex, Norwood, NJ, 1986.]

Schachter, Paul (1985) "Parts-of-Speech Systems," Language Typology and Syntactic 
Description: Clause Structure, ed. by Timothy Shopen, 3-61, Cambridge University Press, Cambridge.

Schwartz, Linda (1988) “Asymmetric Feature Distribution in Pronominal 'Coordinations'," Agreement in Natural Language: Approaches, Theories, Descriptions, ed. by Michael Barlow and Charles A. Ferguson, 237-249, CSLI Publication, Stanford.

Simpson, Andrew and Zoe Wu (2001) "The Grammaticalization of Formal Nouns and Nominalizers in Chinese, Japanese and Korean," Language Change in East Asia, ed. by Thomas E. McAuley, 250-283, RoutlegeCurzon, London.

Stassen, Leon (2000) “AND-languages and WITH-languages," Linguistic Typology 4, $1-54$.

Stassen, Leon (2001) "Noun Phrase Coordination," Language Typology and Language Universals: An International Handbook, ed. by Martin Haspelmath, 1105-1111, Walter de Gruyter, Berlin.

Traugott, Elizabeth Closs and Graeme Trousdale (2010) "Gradience, Gradualness and Grammaticalization: How Do They Intersect?," Gradience, Gradualness and Grammaticalization, ed. by Elizabeth Closs Traugott and Graeme Trousdale, 19-44, John Benjamins, Philadelphia.

Traugott, Elizabeth Closs and Graeme Trousdale, eds. (2010) Gradience, Gradualness and Grammaticalization, John Benjamins, Philadelphia.

Vassilieva, Masha and Richard K. Larson (2005) "The Semantics of Plural Pronoun Constructions," Natural Language Semantics 13, 101-124.

Warner, Anthony (1997) "The Structure of Parametric Change, and V-Movement in the History of English," Parameters of Morphosyntactic Change, ed. by Ans van Kemenade and Nigel Vincent, 380-393, Cambridge University Press, Cambridge.

Whitman, John (2000) "Relabelling," Diachronic Syntax, ed. by Susan Pintzuk, George Tsoulas and Anthony Warner, 220-238, Oxford University Press, Oxford.

[received April 20 2010, revised and accepted August 9, 2010]

College of Humanities

Ibaraki University

2-1-1 Bunkyo, Mito

Ibaraki 310-8512

e-mail: kn20@mx.ibaraki.ac.jp 